\title{
Changing Workspace and Rising Precarity: When Work and Family Come Together
}

\author{
Sruti Kanungo ${ }^{1}$ and Vibha Chaturvedi ${ }^{2}$ \\ ${ }^{1}$ Assistant Professor (Sociology), Symbiosis Law School, \\ Symbiosis International University, Pune, India \\ ${ }^{2}$ Symbiosis Law School, Symbiosis International University, Pune, India
}

\section{ABSTRACT}

In a situation that demands shifting one's professional environment into personal space, it becomes significant to understand its influence on work ethics and social relations. This article focuses on the experiences of the software engineers in India, who are allowed to work-from-home for more than once a week. But when work-from-home became a compulsion, a change in work-life and work-family relations was marked. This paper attempts to study how the blurring thresholds of work $\mathrm{Ct}$ home space require an understanding of the implications of a new work process and rethinking precarity concerning the deflating boundaries.

\section{KEY WORDS: IT PROFESSIONALS, PRECARITY, WORKPLACE CHANGE, WORK FROM HOME, WORKING CONDITIONS.}

\section{INTRODUCTION}

Throughout times we have witnessed many changes in the work process and working styles of the people. Engels in The Condition of the Working-class in England (1845), discussed the problems faced by industrial workers. When industrial society began to undergo profound changes from the 1970s onwards, it paved the way for a post-industrial society marked by the growth of service sectors and white-collar jobs. Daniel Bell's 'The Coming of the Post-Industrial Society' gave an idea of how a transformation toa service sector society and the ensuing new age jobs were defined increasingly by the use of information technology (Strangleman and Warren, 2010).

\section{ARTICLE INFORMATION}

Received 10th Oct 2020 Accepted after revision 15th Dec 2020 Print ISSN: 0974-6455 Online ISSN: 2321-4007 CODEN: BBRCBA

Thomson Reuters ISI Web of Science Clarivate Analytics USA and Crossref Indexed Journal

\section{Clarivate
Analytics}

NAAS Journal Score 2020 (4.31)

A Society of Science and Nature Publication,

Bhopal India 2020. All rights reserved.

Online Contents Available at: http//www.bbrc.in/

Doi: http://dx.doi.org/10.21786/bbrc/13.15/29
But in India, as Chitra Joshi, remarks, labour history emerged in the post-colonial period.

Prior to that, in the 1950 s and 60 s, the colonial discourse on labour brought out a lack of commitment to work and irregular work rhythms. The writers of late 1970s focused on how caste and village ties played a significant role in among the working class and how working-class protest emerged (Joshi 2000). The shift marked during the 1980s was classified as a discursive structure and then questioning of earlier notions of class and class consciousness (ibid.). But with the growth of the neo-liberal global market, in 1990, and flourishing technological and communication revolution, increased work flexibility was witnessed. But even with work flexibility, there are certain professional ethics that the employees are made to follow.

Emile Durkheim (1957 [1992]) remarked that the professional ethics that govern individuals, compel them to act in a way, impose limits to their inclinations and forbid them to go beyond. These regulations and moral standards put an end to the conflict that disturbs life. Therefore these rules telling each of the workers his rights and duties, must not be vague or written in general 
terms but must be precise, detailed and taking into consideration the most ordinary day-to-day occurrences. Although in a different context, Kamala Sankaran rightly argued that with the changing scenario in the 1990s, the Declaration on Fundamental Principles and Rights at Work (DFPR) by the International Labour Organization (ILO) in 1998 to effectively monitor the compliance with labour standards everywhere is a significant decision (Sankaran 2013).

DFPR mandates ILO to conform to the fundamental principles and rights at work particularly in the areas relating to freedom of association and right to collective bargaining, the elimination of forced or compulsory labour, abolition of child labour and elimination of discrimination in employment and occupation (ibid.). Various reports and academic writings have discussed on compensation to employees, income inequality, a decline of unions and redistributive role work flexibility, globalization of competition between workers, changes in collective bargaining structures, and welfare state provisions (Michele Lamont 2011 et.al.). But today it becomes significant to look from the other side particularly with growing flexibilities and deflating bounds of work and personal life that lead to conflicting personal responsibilities and professional roles.

Arguments of the paper are based on interviews and the use of questionnaires with IT professionals to enter their worlds of work that is not much explored. Telephonic interviews with ten and questionnaires in form of google forms sent to the sixty IT professionals (inc. those interviewed) in order to understand their experiences on their changing work process and the influence of rising flexibility on the employees. Convenient and snowball sampling was used to get the contacts of the respondents of which thirty-five were male and twenty-five were female aged between 21-40 years and are continuing in the work for more than one year. 26 out of 35 males and 13 of the 25 female were also married.

Twenty-eight of the married respondents have children. The study was conducted between May-June 2020, after two months of lockdown announced from timeto-time by the state due to severity of the situation and these professionals were asked to work from home for more than two months. The sector comprises of nearly 1.2 million people of six leading corporate companies. These professionals, who are usually allowed to work from home when required, revealed interesting stories of their increasing levels of work-stress, uncertainties regardingjob security, and restricted movement and confinement. They revealed how the transition of the workplace to home space also change the work ethics and social and personal relations.

The paper is divided into three sections that begin with a brief overview of literature related to work and precarity. The next section brings out the arguments to the workplace changes and its implications on the IT professionals, how space plays a major role when we discuss 'work' and how the blurring boundaries between work and home space can lead to new work precarity. The last section is the concluding section that discusses the need for discussing the implications and rethinking the precarity in the context of the collapsing boundaries.

Changing Workplace and Rising Precarity: The term "precarity" originating from the Latin root prex or precis, referred to "to pray, to plead," and it commonly implies risky or uncertain situations (Maribel Casas-Cortés, 2014: 206). It gained importance in the 1990s, in Europe, as a response to the unstable labour relationship, usually associated with a lower salary and less protection against firing (ibid. 209). Rodgers and Rodgers (1989) developed four dimensions of precarious jobs for the International Labour Organization (ILO):

1. uncertainty over the continuity of employment;

2. a lack of individual and collective control over wages and conditions;

3. low or no levels of social protection against unemployment, discrimination, etc.; and

4. insufficient income or economic vulnerability

Although the level precarity, according to ILO report, varies based on a country, region, and the economic, political and social structure, as well as the labour markets, certain characteristics are common in every country or region (ILO 2011). These include uncertainty on the duration of employment, multiple possible employers, a disguised or ambiguous employment relationship, lack of access to social protection and benefits usually associated with employment, low pay, and substantial legal and practical obstacles to joining a trade union and bargaining collectively (ibid.). In a neoliberal globalized era marked by technological advances, the state regulations on minimum acceptable standards in the labour market got eroded like the rules that governed competition in product markets (Arne L. Kalleberg 2009).

Flexibility at the workplace resulted in restructuring and transformations in the employment relationship. Kalleberg rightly remarks that in transitional and less developed countries the term precarious work is affixed with the informal workforce. But precarity, in short, as Andrea Muehlebach is shorthand for those of us documenting the multiple forms of nightmarish dispossession and injury that our age entails (Muehlebach 2012). According to Vosko (2010, p. 51), the standard employment relationship (SER) is "a regulatory architecture built upon employment status (i.e., the bilateral employment relationship), standardized working time (normal daily, weekly, and annual hours), and continuous employment (permanency)" (see Dennis Arnold and Joseph R. Bongiovi 2013: 294). Absence of any of these features often leads to the growth of uncertainty and precarity in the work process.

Precarity, in the Indian context, is often been associated with the informal workforce that includes self-employed petty commodity producers, migrants, women and child 
workers. But in a situation marked by crises due to a global pandemic, it becomes significant to understand its influence on different sections of the society. The announcement of national lockdown on March 24, 2020, due to national health emergency arising out of COVID 19 outbreak, left many informal migrant workers stranded.

Reports of these thousands of daily wage workers without food or money, struggling to reach their home state safely made news everywhere. The impact was also noticed in the transportation and manufacturing sectors, street sellers, small shop owners, artisans, domestic help and construction workers. Not just the informal workers, but also private corporate employees' witnessed a severe blow with this transition. It not only influenced their lives and livelihood but also social and occupational relation thus causing severe work stress and work-life imbalance.

\section{When Work and Family Come Together: Role of Space in a Corporate Sector: Lack of adequate internet connectivity and a room entirely dedicated to the work setup, it becomes stressful to work remotely from home. Talking for myself being a developer I need my mental peace to concentrate properly while coding. But working from home and knowing that your baby requires your attention all the time it becomes very difficult not getting a few hours in a day to yourself. (- Mother of a 2 years kid \&t Project Lead).}

There was news about attempts by employers to ensure that high-speed broadband connectivity is provided to remote workers, expanding their own virtual private network bandwidth by ten times and also shipping 35,000 computers to employee residences to make sure that the employees continue with their work. But working from home for a longer time makes it significant to understand the space limitations, technological constraints. While many participants of the study pointed out that work from home allowed them to be at home, taking out time for housework, no feeling of rush or reaching on time, no anxiety of traffic or travel, flexible eating timings. But these flexibilities also brought with it feelings of isolation, stress that could have been resolved by speaking to colleagues if they were at the office. Given the advantages of working from home, the need is also to understand the drawbacks and problems it withholds.
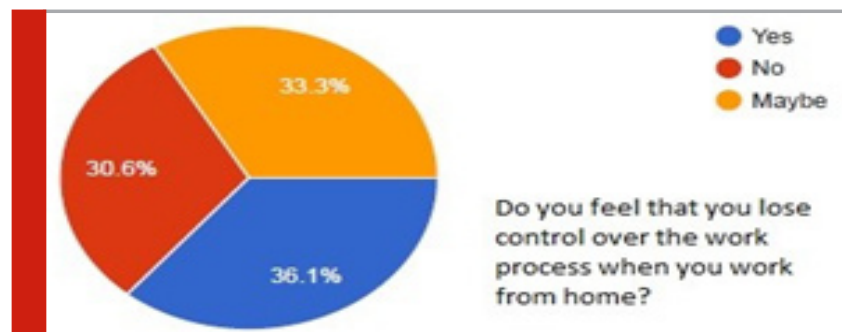

At the office, work gets done faster compared to home. Because we reach out to correct people and discuss in face to face to solve the issue. In work from home situation, we have to find a time to schedule a call and generally the time is taken to finish the work is more compared to the office (Male 33, Business Analyst).

Working from home often brings with it different types of challenges like technical issues that you cannot resolve immediately, issues of adequate internet connection due to which I go offline many a times and miss out several important points by the time I connect back. This gives me stress and anxiety and the thought of losing my job, inability to find another job. Further, there is a drop in the knowledge growth when work from home becomes a regularity and normality. This is because we don't get the surrounding or people with whom we can sit for a cup of tea or coffee and discuss certain issues or problems. There is a lack of connectedness with others in such a situation. The relocation of work has not only changed the work-life balance but also changing roles of the family members (Lead analyst, 36, Female).

Anthony Giddens (2009) rightly remarks that sociological imagination requires us, above all, to 'think ourselves away' from the familiar routines of our daily lives in order to look at them anew. To this, he gives the example of the simple act of drinking a cup of coffee. It is not just a simple act of consuming the drink or just a refreshment (ibid. 6-8). It is not just an individual activity but holds symbolic and social values. When two people meet over coffee they are more interested in getting together, chatting or discussing over an issue rather than just to drink. Further, in every society, drinking and eating provide occasions for social interaction and the enactment of rituals. Giddens rightly remarks that our activities give shape to the social world around us and, at the same time they structured by that social world. But in a situation where these activities are disrupted, it becomes significant to understand the impact of such changes on society. It was reported by man respondents that being away from the workplace, makes them feel a loss of connection with work ethics and unconstrained interaction with colleagues to resolve an issue or get the work done.

Alan Felstead and Nickwe Jewson referred to diverse frontiers that the home-located producers confront and try to negotiate. The foremost among these is the management of boundaries between the household and the outside world. Then after is the organisation of boundaries between the household and the outside world (Felstead and Nickwe 2000: 143). Lack of proper organization and clear division of boundaries can become unwelcoming, also lead to a lack of privacy and anxiety. It is rare in case of many employees that their home is optimized into space specifically dedicated for work. As an outcome many end up locking themselves in their bedroom/guest room or their drawing rooms with a background noise of television, doorbell and utensils. These situations further aggravate when there is no fixity of work timings.

At home, workload increases and with it the level of anxiety... getting calls to finish the work even after work hours has become a real challenge. This has instead 
increased personal life problems. Along with work, a person has a family that they have to look after. I and my partner are both working and have a 5 years old son. We have to take care of him and his studies. Although we do take turns there are certain times when both of us get busy and he is left all alone. This would not have been a problem if we had a 24X7 house help or living in a joint family with our parents. We do have a cook who comes, cooks and leaves. But other household chores need to be completed and we cannot expect one partner to do all the household chores.

Although we take turns to do the work, but managing work from home and household chores at the same time becomes difficult. It becomes difficult to draw boundaries and specify specific timings to each work. Night duties from home add to the difficulties when one has to talk slowly to the client or while making a presentation to ensure that the entire family's sleep is not disturbed. This would not have happened if I would have been in office. I have to think several times to make a cup of tea/coffee late night and the reason is the same. All these would not have been difficult had I been in office (Senior team lead, 37, Male). The table below shows the responses of the professionals:

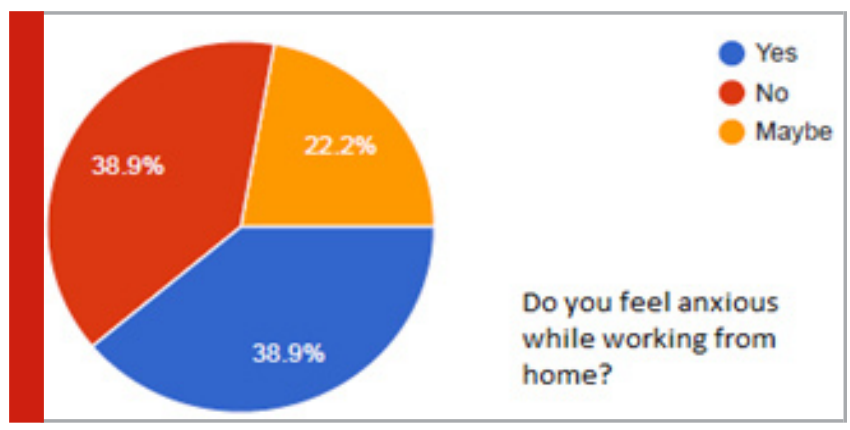

These challenges made it difficult for employees to organise themselves and their timings. Irregular working hours, no fixity of work timings led many to witness family conflicts. Maintaining work ethic, meeting the deadline along with organising one's time, space and family responsibilities led to a new precarious situation for the employees. It was noted by many that although they were not under any managerial surveillance, psychological pressure increased. This was due to the assumption that they are at home so they are available to do the work whenever required. Managers tried to reach them anytime via phone, mails or messages even at odd times.

While working from home has mitigated my commute challenges and improved my health, but on the flip side, it has also allowed my reporting managers to reach me at odd hours presuming I am always at home and always available with my laptop (Female, 34, Support Analyst). Although in a different context, Richenda Gambles et.al (2006) rightly remarks that the difficulties of combining paid work with other parts of life, family relationships and well-being is no longer personal, family, employer or even national concerns, instead they have become global challenges (2006: 5). The changing roles, identities, and relationships in the context throw new challenges and societies as a whole need to respond to the changes in families, work, workplaces and communities in an increasingly globally connected world (ibid.).

Harmonising paid work with other parts of life that include family, friends, relatives, unpaid care and domestic work and community participation are interrelated and thus demands utmost balance (ibid. 35). Further, while the roles and responsibilities of men and women related to their work and family have evolved and have become increasingly reciprocal and dynamic, it becomes significant to overcome other deterrents in form of remorseless, unusual, odd work timings leading to strain, worry, anxiety and thus precarity. Adapting to the changing needs also entails, on the part of the authorities, adapting to certain norms, rules and standards in their working practices in order to ensure smooth functioning and lower the risk of the precarious working condition.

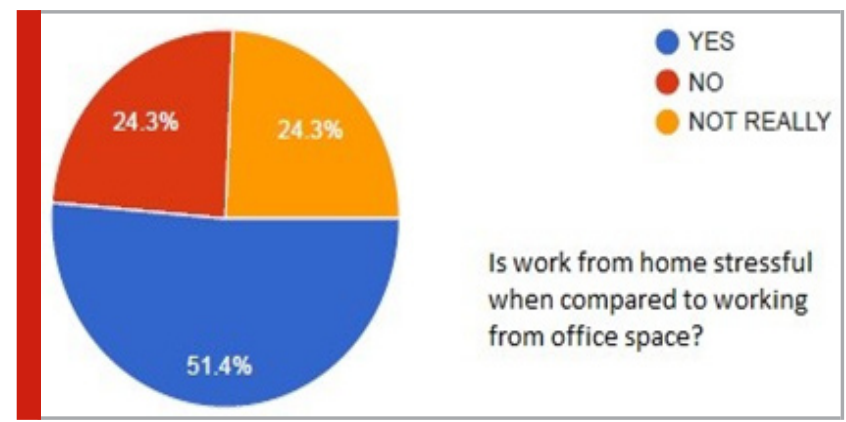

A report by Global Workplace Analytics had estimated a 159\% increase in work from home between 2005 and 2017. The unprecedented disruption caused by Covid-19 has certainly led to an unprecedented increase in this percentage. Though many people fathom it to be an easily manageable affair by simply equipping people with laptops, what they fail to realise are the myriad challenges both personal, social and professional that it has caused by rupturing a structured routine.

Laurel Farrer, the co-founder of the Remote Work Association and CEO of Distribute Consulting, is of the opinion that in the absence of robust policies and procedures to support off-site employees, work from home is likely to have unpleasant personal and professional consequences including micromanagement, career stagnancy, isolation and mental and physical burnout. Moreover, technical difficulties associated with this work format (signal issues and internet downtime) exacerbate the stress of an IT professional. Motivating yourself and staying focussed in the comforts of home, along with its distractions, is a major challenge of remote working. Teamwork, which is considered to be a mainstay of IT work culture, has been hampered in these challenging times with video calls being the closest one can get.

Looking at the economics of remote working, an article in Economic Times (May 31, 2020) aptly pointed out that while organisations may be benefitting from the 
economics of working from home amidst lockdown and virus spread scare, retail/individual power usage bills have approximately doubled with increased use of air conditioners, lights, fans and other peripheral gadgets to support uninterrupted working. With stagnant disposable incomes, and in many cases even declining incomes owing to pay cuts, and in the absence of any compensation towards inflated bills, the incidence on individuals is definitely higher and pressing. At a macro level, one must not overlook the inequalities of access and opportunity, which was quick to fizzle out the work from home euphoria. The debates on advantages and disadvantages of remote working and its long term adverse impacts became more vociferous when companies like Google, Microsoft and Facebook announced extension till end of year.

If we analyse the more minute details, the ergonomic furniture of working spaces in largely absent at home, which has impacted posture and comfort of long hours of working at the laptop. Most of the newly recruited younger professionals cannot afford to install PCs or buy laptop to support their jobs. This is apart from the free tea and coffee breaks that come as perks to all the office goers. All this discussion has, till now, been associated with tier I and II cities. The challenges related to continuous connectivity of high bandwidth increase in semi urban and rural areas which suffer from poor signals caused by lack of towers and service providers. Huge disparities between countries and sectors has emerged when employees are largely unable to work from home.

While around $60 \%$ of workers in high income countries like the US and Switzerland are unable to fully work from home, in poor nations like Bangladesh and Egypt this number is as high as $80-90 \%$ owing to digital connectivity issues and the sectors in these economies. Additionally remote working has adversely impacted productivity due to hampered flow of communication, stress caused by the spreading pandemic and increase in unpaid home care responsibilities. The focus of organisations has now shifted to maintaining and managing deteriorating mental health of employees after a UK study report found the anxiety levels to be higher in March-April 2020. (WEF article from Future of Jobs Report, 2020).

Apart from this double disruption caused by Covid 19, there are going to be some unavoidable consequences which are likely to change IT sector operations and delivery in more ways than one by 2025, according to WEF Report. The pace and extent of mechanization will increase and the adoption of technology will now be a priority of business leaders. Consequent to technology integration, companies are estimated to prune their workforce, migrate to contractual workforce hiring, shift locations and modify value chains. Number of jobs created is likely to be lesser than number of jobs created and skill gap will stay with skills like critical thinking, analysis, problem solving, emotional intelligence, self-management and flexibility will witness a rise in demand.

As skills are highly correlated to social inequalities, this emerging skill gap of soft \& basic and cross functional skills will exacerbate the need for re-skilling. It is also likely to significantly impact jobs of lower wage workers, women and young workers and further deepen the inequalities. Those in employment and those unemployed will both look for cross skilling and acquiring latest digital skills to reduce the uncertainties caused by Covid19. So human capital investment, which was the central theme of Nobel Laureate Amartya Sen's developmental economics, will gain currency with a renewed focus. With India at the 116th position out of 15 countries in World HCI 2020, according to World Bank Report, skill development becomes central to government in order to sustain its top position as favourable destination for outsourced business. Pandemic has put at risk a decade's progress in human capital which is now vital to a more inclusive, sustainable and futuristic growth.

\section{CONCLUSION}

Over the past decades, the growth of white-collar service work has led to the end of many problems related to industrial, blue-collar services. But at the same time, the sector has also introduced new forms of precarity under the aegis of 'new normality'. It raises some significant questions about the precarity of the situation, the stress attached to it and the blurring boundaries between work \& t home space. While precarity has often been associated with rising unemployment, job insecurity, non-standard work conditions, low or no workplace safety, work stress and harassment and, growing risk and uncertainty.

The point here is to note that whether blurring boundaries have reduced or instead increased the precarity of the employees. Instances of no fixed work timings, lack of dedicated workplace at home for many, work stress to meet deadlines and targets, breaking of work ties, anxieties related to network issues while meeting a client and rising family conflicts still questions the efficiency of 'new normality'. The potential risk associated with the work from home situation is difficulty in establishing the boundaries and thus lack of relaxation and feeling of isolation makes us rethink the 'new' precarity associated with the 'new' normality.

\section{REFERENCES}

Bongiovi, A. a. (2013). 'Precarious, Informalizing, and Flexible Work : Transforming Concepts and Understandings'. American Behavioral Scientist, SAGE Publications57(3): 289-308.

Bourdieu, P. ( 1998). 'Job Insecurity is Everywhere Now' In P. Bourdieu, Acts of Resistance Against the New Myths of our Time. Great Britain: Polity Press and The New Press, 81-87.

Casas-Cortés, M. (2014). 'Marxism:, A Genealogy of Precarity: A Toolbox for Rearticulating Fragmented 
Social Realities in and out of the Workplace'. Rethinking Marxism: A Journal of Economics, Culture Ct Society26(2): 206-226.

Durkheim, E. 1957 (1992). Professional Ethics and Civic Morals. London: Routledge.

Felstead, Alan and Jewson, Nick. 2000. In Work, At Home: Towards an Understanding of Homeworking. Taylor \& Francis: Routledge.

Gambles, Richenda, Suzan Lewis and Rhona Rapoport. 2006. The Myth of Work-Life Balance: The Challenge of Our Time for Men, Women and Societies

Giddens, Anthony. 2009. Sociology. Cambridge: Polity Press

Hewison, A. L. (2013). 'Precarious Work and the Challenge for Asia'. American Behavioral Scientist, SAGE Publications 57(3):271- 288.

Hislop, D. and C. Axtell (2009), 'To Infinity and Beyond? : Workspace and the Multi-location Worker', New Technology, Work and Employment 24 (1): 60-75.

Joshi, Chitra. 2006. Lost Worlds Indian Industrial Labour and its forgotten History. Delhi: Permanent Black.

Kalleberg, A. L. (2009). 'Precarious Work, Insecure Workers: Employment Relations in Transition'. American Sociological Review74:1-22.

Lamont, Michele Caitlin Daniel, Eleni Arzoglou. 2011. 'European Workers: Meaning-Making Beings'. In David Brady ed. Comparing European Workers Part B: Policies and Institutions David Brady ed. Comparing European Workers Part B: Policies and Institutions U.K.: Emereld, Pp: 287-312.

Muehlebach, A. (2013). 'On Precariousness and the Ethical Imagination: The Year 2012 in Sociocultural
Anthropology'. American Anthropologist115 (2): 297-311.

Sankaran, Kamala. (2013). 'Domestic Work, Unpaid Work and Wage Rates'. Economic and Political Weekly 48(43): 85-89.

Stanford Institute of Economic Policy Research (SIEPR) (June 2020). How Working from Home Works Out. Nicholas Bloom

Strangleman, Tim and Tracey Warren,. (2010). Work and Society: Sociological Approaches, Themes and Methods. London and New York: Routledge.

The World Bank, 2020. Human Capital Project

World Economic Forum, October 2020, Future of Jobs Report 2020. https://economictimes.indiatimes.com/ tech/ites/it-campuses-will-never-be-the-same-howindias-4-million-it-workers-shifted-to-working-fromhome-overnight/articleshow/75290054.cms?utm source $=$ contentofinterestCtutm_medium =text\&utm_ campaign=cppst )

https://www.ilo.org/wcmsp5/groups/public/--ed_dialogue/---actrav/documents/meetingdocument/ wcms_ 164286.pdf

https://indianexpress.com/article/opinion/covid-19crisis-sharad-yadav-india-lockdown-migrant-workers6398931/

https://botpopuli.net/covid19-precarity-pandemiccrisis-in-india-informal-labor-markets

https://economictimes.indiatimes.com/tech/ites/ it-campuses-will-never-be-the-same-how-indias4-million-it-workers-shifted-to-working-fromhome-overnight/articleshow/75290054.cms?utm source $=$ contentofinterestctutm_medium $=$ textctutm campaign=cppst 